\title{
Neutron Detection with Mercuric Iodide
}

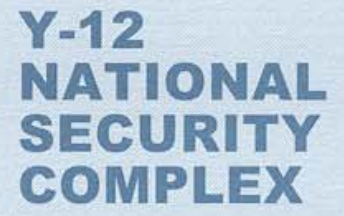

$Y-12$ NATIO SECURITY COMPLEX

\author{
Z. W. Bell \\ Y-12 National Security Complex \\ Ken R. Pohl, Lodewijk van den Berg \\ Constellation Technology Corporation
}

Date of Issue: June 17, 2003 


\section{DISCLAIMER}

This report was prepared as an account of work sponsored by an agency of the United States Government. Neither the United States Government nor any agency thereof, nor any of their employees, makes any warranty, express or implied, or assumes any legal liability or responsibility for the accuracy, completeness, or usefulness of any information, apparatus, product, or process disclosed, or represents that its use would not infringe privately owned rights. Reference herein to any specific commercial product, process, or service by trade name, trademark, manufacturer, or otherwise, does not necessarily constitute or imply its endorsement, recommendation, or favoring by the United States Government or any agency thereof. The views and opinions of authors expressed herein do not necessarily state or reflect those of the United States Government or any agency thereof.

\section{COPYRIGHT NOTICE}

The submitted manuscript has been authorized by a contractor of the U. S. Government under contract DE-AC05-00OR-22800. Accordingly, the U. S. Government retains a paid-up, nonexclusive, irrevocable, worldwide license to publish or reproduce the published form of this contribution, prepare derivative works, distribute copies to the public, and perform publicly and display publicly, or allow others to do so, for U. S. Government purposes. 


\title{
Neutron Detection with Mercuric Iodide
}

\author{
Z. W. Bell \\ Y-12 National Security Complex \\ Ken R. Pohl, Lodewijk van den Berg \\ Constellation Technology Corporation
}

Date of Issue: June 17, 2003

Prepared by the Y-12 National Security Complex

P. O. Box 2009,

Oak Ridge, Tennessee 37831-8169 managed by BWXT Y-12 L.L.C.

for the

U.S. DEPARTMENT OF ENERGY

under contract DE-AC05-00OR-22800 
Neutron Detection with Mercuric Iodide

Z. W. Bell

Y-12 National Security Complex

Ken R. Pohl, Lodewijk van den Berg

Constellation Technology Corporation

Mercuric iodide is a high-density, high- $Z$ semiconducting material useful for gamma ray detection. This makes it convertible to a thermal neutron detector by covering it with a boronrich material and detecting the $478 \mathrm{keV}$ gamma rays resulting from the ${ }^{10} \mathrm{~B}(\mathrm{n}, \alpha)^{7} \mathrm{Li}^{*}$ reaction [1]. However, the 374 barn thermal capture cross section of ${ }^{\text {nat }} \mathrm{Hg}$, makes the detector itself an attractive absorber, and this has been exploited previously [2]. Since previous work [3-6] indicates that there are no low-energy gamma rays emitted in coincidence with the $368 \mathrm{keV}$ capture gamma from the dominant ${ }^{199} \mathrm{Hg}(\mathrm{n}, \gamma)^{200} \mathrm{Hg}$ reaction, only the $368 \mathrm{keV}$ capture gamma is seen with any efficiency a relatively thin (few $\mathrm{mm}$ ) detector. In this paper we report preliminary measurements of neutrons via capture reactions in a bare mercuric iodide crystal and a crystal covered in ${ }^{10} \mathrm{~B}$-loaded epoxy. The covered detector is an improvement over the bare detector because the presence of both the 478 and $368 \mathrm{keV}$ gamma rays removes the ambiguity associated with the observation of only one of them. Pulse height spectra, obtained with and without lead and cadmium absorbers, showed the expected gamma rays and demonstrated that they were caused by neutrons.

Acknowledgement

This work supported by the U.S. Department of Energy under contract DE-AC-05-00OR22800.

References:

1. Zane W. Bell, US Patent 6011266, Jan. 4, 2000.

2. Albert G. Beyerle and Kenneth L. Hull, Nucl. Inst. Meth. In Phys. Res. A256, p. 377, 1987.

3. R. E. Segel, Phys. Rev. 111 No. 6, p. 1620, 1958.

4. R. E. Segel, R. K. Smither, and R. T. Carpenter, Phys. Rev. 133 No. 3B, p. B583, 1964.

5. G. A. Bartholomew, S. I. H. Naqvi, M. R. Gunye, and E. D. Earle, Can. J. Phys. 45, p. 1517, 1967.

6. D. Breitig, R. F. Casten, and G. W. Cole, Phys. Rev. C, 9 No. 1, p. 366, 1974. 


\author{
Neutron Detection with Mercuric Iodide \\ Z. W. Bell \\ Y-12 National Security Complex \\ Ken R. Pohl, Lodewijk van den Berg \\ Constellation Technology Corporation
}

Abstract- Mercuric iodide is a high-density, high-Z semiconducting material useful for gamma ray detection. This makes it convertible to a thermal neutron detector by covering it with a boron-rich material and detecting the 478 $\mathrm{keV}$ gamma rays resulting from the ${ }^{10} \mathrm{~B}(\mathrm{n}, \alpha)^{7} \mathrm{Li}^{*}$ reaction [1]. However, the 374 barn thermal capture cross section of ${ }^{\text {nat }} \mathrm{Hg}$, makes the detector itself an attractive absorber, and this has been exploited previously [2]. Since previous work [3-6] indicates that there are no low-energy gamma rays emitted in coincidence with the $368 \mathrm{keV}$ capture gamma from the dominant ${ }^{199} \mathrm{Hg}(\mathrm{n}, \gamma)^{200} \mathrm{Hg}$ reaction, only the $368 \mathrm{keV}$ capture gamma is seen with any efficiency a relatively thin (few $\mathrm{mm}$ ) detector. In this paper we report preliminary measurements of neutrons via capture reactions in a bare mercuric iodide crystal and a crystal covered in ${ }^{10} \mathrm{~B}$-loaded epoxy. The covered detector is an improvement over the bare detector because the presence of both the 478 and $368 \mathrm{keV}$ gamma rays removes the ambiguity associated with the observation of only one of them. Pulse height spectra, obtained with and without lead and cadmium absorbers, showed the expected gamma rays and demonstrated that they were caused by neutrons.

\title{
I. Introduction
}

Mercuric iodide has a 31 year history, beginning with the first paper, in 1972, reporting its use as a roomtemperature gamma ray detector [7]. From then through 1983, the maximum size of available crystals grew exponentially from $2 \mathrm{~mm}^{3}$ to $10 \mathrm{cc}$ [8], and Knoll [9] mentions one with a volume of $19.2 \mathrm{cc}$. Today they are routinely available with area $25 \mathrm{~cm} \times 25 \mathrm{~cm}$, and thickness up to a few millimeters.

When account is taken of the density and mass attenuation coefficient of $\mathrm{HgI}_{2}$, large volume crystals are attractive for use in neutron detectors that rely on the detection of a capture gamma ray. Among materials with sufficient capture cross section, ${ }^{10} \mathrm{~B}$ stands out because there is only a single gamma ray emitted subsequent to capture, and the signature is easy to analyze (although it is Doppler broadened). However, it is necessary to have a photopeakefficient detector to take advantage of the $478 \mathrm{keV}$ gamma ray from the boron reaction, and mercuric iodide, with a linear attenuation coefficient of $0.316 \mathrm{~cm}^{-1}$ at this energy, would be expected to have reasonable efficiency.

As reported by Beyerle [2], $\mathrm{HgI}_{2}$ itself will signal the presence neutrons by developing a peak at $368 \mathrm{keV}$, corresponding to emission from the first excited state of ${ }^{200} \mathrm{Hg}$. This gamma ray is emitted in $81 \%$ of captures and has a single interaction probability averaged over a $3 \mathrm{~mm}$ thick crystal of $17 \%(8.7 \%$ photoelectric absorption probability). It appears in the spectrum from a thin crystal precisely because the emitting state is populated by cascades producing primarily high-energy $(>1 \mathrm{MeV})$ gammas that are essentially invisible to the detector. This occurs because the total (Compton plus photoelectric plus pair production) interaction probability between 1 and 6 $\mathrm{MeV}$ averaged over a $3 \mathrm{~mm}$ thick crystal is approximately $4.6 \%$, making it unlikely that a high-energy photon from high in the cascade interacts in a crystal simultaneously with a $368 \mathrm{keV}$ photon. The attenuation coefficient for thermal neutrons is $3.13 \mathrm{~cm}^{-1}$, implying that a $3 \mathrm{~mm}$ thick crystal is approximately optimal since neutron captures by mercury will occur essentially uniformly throughout the detector.

\section{Measurements}

A $25 \mathrm{~mm}$ x $25 \mathrm{~mm}$ x $2.6 \mathrm{~mm} \mathrm{HgI}$ crystal (mounted in a Constellation Technology Mercury Module ${ }^{\mathrm{TM}}$ ) was biased at 2500 volts, connected to a shaping amplifier (12 microseconds shaping time), which was connected to an analogto-digital converter. The gain of the system was adjusted for approximately $1 \mathrm{keV} / \mathrm{channel}$. Data were acquired for 500 seconds.

Thermal neutron spectra were obtained by placing the detector inside a port in moderator of an Am-Li neutron source producing approximately $100 \mathrm{n} / \mathrm{cm}^{2} / \mathrm{s}$. The Am-Li source was contained in a W-Ni-Fe shield contained within polyethylene. A set of concentric lead ( $1 \mathrm{~cm}$ thick) and cadmium ( $0.5 \mathrm{~mm}$ thick) cups was available to attenuate the gamma and neutron fluxes present in the port. The lead cup fit inside the cadmium. Use of these cups separately and simultaneously distinguished the responses to the two radiations. 


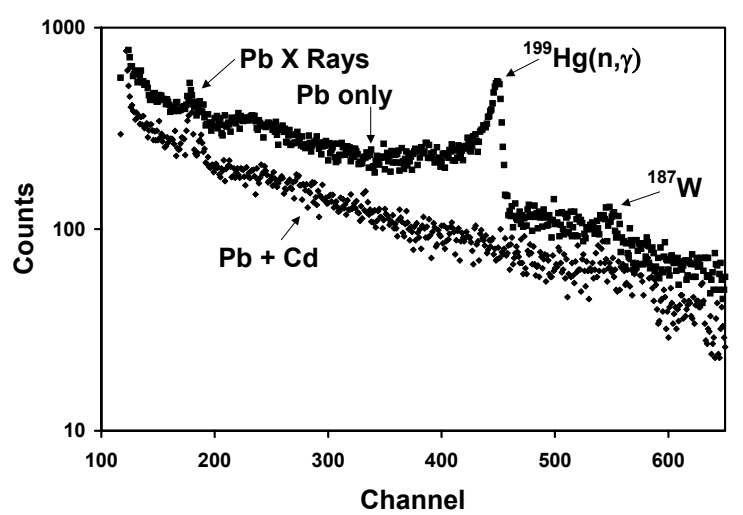

Figure 1. Spectrum from bare detector

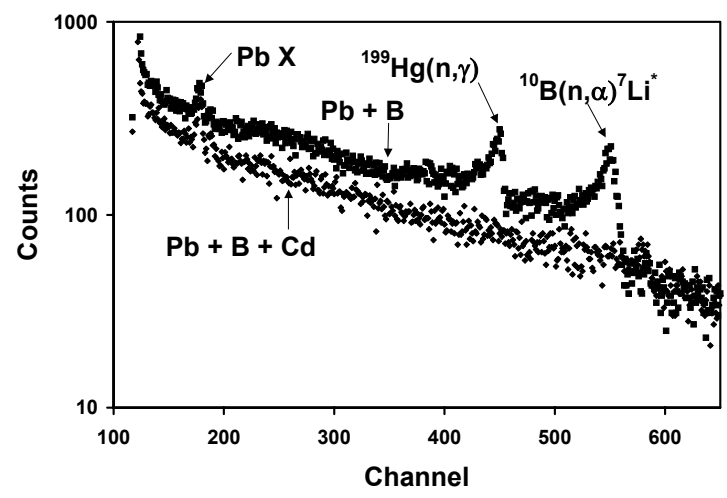

Figure 2. Spectrum from boron-covered detector
Figure 1 shows spectra obtained from a bare detector. Note the logarithmic scale and suppressed origin. The upper spectrum results from placing the detector in the lead cup and omitting the cadmium cup. The $368 \mathrm{keV}{ }^{199} \mathrm{Hg}(\mathrm{n}, \gamma)$ peak is clearly visible. In addition, a faint peak due to radioactive ${ }^{187} \mathrm{~W}(480$ $\mathrm{keV}$ ) is visible near channel 550. This isotope is produced in the W-Ni-Fe shield. The lower spectrum results from inserting the lead cup and detector in the cadmium cup. The neutron response is eliminated; fluoresced lead $\mathrm{x}$ rays are visible near channel 200 in both spectra.

Figure 2 shows spectra obtained from a detector covered with a $0.5 \mathrm{~mm}$ thick wafer of ${ }^{10} \mathrm{~B}$-loaded epoxy. Boron loading was $32 \%$ by weight, yielding a boron density of $0.44 \mathrm{~g} / \mathrm{cc}$, and a wafer that is black to thermal neutrons. Both gamma rays are detected and are clearly visible.

\section{Conclusions}

While the presence of $368 \mathrm{keV}$ gamma rays is an indication of neutrons, there is no assurance that that is the only source. Lawrence Berkeley National Laboratory's listing [10] of radioactive decay gammas includes 18 lines in the range $360-375$ $\mathrm{keV},{ }^{131}$ I among them. This is common medical isotope, which, although having other gamma rays,

could confuse an unsophisticated analysis. Similarly, there are 22 decay gammas in the range $468-486 \mathrm{keV}$. However, there is only a single isotope in common, ${ }^{192} \mathrm{Ir}$, an industrial isotope emitting strongly at 468 , weakly at 484 , and even more weakly at $374 \mathrm{keV}$. Thus, although an iridium source would present gamma rays of roughly the correct energy, they would not appear in the correct ratio to be mistaken for neutrons. It would require the presence of multiple isotopes to simulate the neutron signature developed by a boron-coated $\mathrm{HgI}_{2}$ crystal. However, if the simulants have different half-lives, then the simulation will become imperfect with increasing time. This scenario to fool the detector assumes, of course, that the spectrum is not analyzed for other gamma rays.

Acknowledgement

This work supported by the U.S. Department of Energy under contract DE-AC-05-00OR22800.

References

1. Zane W. Bell, US Patent 6011266, Jan. 4, 2000.

2. Albert G. Beyerle and Kenneth L. Hull, Nucl. Inst. Meth. In Phys. Res., A256, p. 377, 1987.

3. R. E. Segel, Phys. Rev. 111 No. 6, p. 1620, 1958.

4. R. E. Segel, R. K. Smither, and R. T. Carpenter, Phys. Rev. 133 No. 3B, p. B583, 1964.

5. G. A. Bartholomew, S. I. H. Naqvi, M. R. Gunye, and E. D. Earle, Can. J. Phys. 45, p. 1517, 1967.

6. D. Breitig, R. F. Casten, and G. W. Cole, Phys. Rev. C, 9 No. 1, p. 366, 1974.

7. H. L. Malm, IEEE Trans. Nucl. Sci., NS-19, p. 263, 1972.

8. M. Schieber, Nucl. Inst. Meth., 213, p. 1, 1983.

9. Glenn F. Knoll, Radiation Detection and Measurement, $3^{\text {rd }}$ Edition, John Wiley and Sons, New York, 2000, p. 485 .

10. Richard B. Firestone, http://ie.lbl.gov/toipdf/glist.pdf. 